\title{
Prescribed drug therapy and near-fatal asthma attacks
}

\author{
C. Burgess, N. Pearce, R. Thiruchelvam, R. Wilkinson, \\ C. Linaker, K. Woodman, J. Crane, R. Beasley
}

Prescribed drug therapy and near-fatal asthma attacks. C. Burgess, N. Pearce, R. Thiruchelvam, R. Wilkinson, C. Linaker, K. Woodman, J. Crane, R. Beasley. CERS Journals Ltd 1994.

ABSTRACT: Inhaled fenoterol has been associated with an increased risk of death in severe asthmatics, when compared to other adrenoceptor agonists. It is plausible that fenoterol may also increase the risk of near-fatal attacks. We have conducted a case-control study to investigate this hypothesis.

The cases comprised Intensive Care Unit (ICU) admissions for asthma in the Wellington region during 1977-1988. For each of these cases, two age-matched controls were selected from asthma admissions to the same hospital during the same period. For the 155 cases and 305 controls, information on prescribed drug therapy was collected from the hospital admission records.

The relative risk of a near-fatal asthma attack in patients prescribed inhaled fenoterol was 2.00 (95\% confidence interval (CI) 1.35-2.97). An increased risk was also observed for oral theophylline (odds ratio $(O R)=1.88 ; 95 \%$ CI 1.26-2.79). For the 65 cases and 104 controls who had a previous admission for asthma in the previous 12 months, information relating to the previous admission was also collected; an increased risk was once again observed for inhaled fenoterol $(\mathrm{OR}=\mathbf{2 . 1 8}$; $95 \%$ CI 1.10-4.33) and for oral theophylline (OR $=1.18$; 95\% CI 0.99-3.57). No other asthma drugs showed significantly increased risks. Although the ICU admission cases had generally been prescribed more asthma drugs than the hospital admission controls, and appeared to have more severe asthma, it is possible that the findings reported here are influenced by confounding by severity.

We nevertheless estimate that our findings are consistent with the hypothesis that fenoterol increases the risk of near-fatal asthma attacks, and that they complement previous findings on fatal asthma attacks. They also provide some support to previous concerns about the safety of oral theophyllines, although the evidence for this is less consistent.

Eur Respir J., 1994, 7, 498-503.
Dept of Medicine, Wellington School of Medicine, Wellington, New Zealand.

Correspondence: C. Burgess

Dept of Medicine

Wellington School of Medicine

PO Box 7343

Wellington South

New Zealand

Keywords: Asthma

epidemiology

fenoterol

theophylline

Received: January 51993

Accepted after revision October 211993
Three previous New Zealand case-control studies of asthma deaths in the 5-45 yrs age-group during 1977-1987 have found that inhaled fenoterol is associated with an increased risk of death in severe asthmatics [1-3]. These findings have been supported by a recent study in Saskatchewan [4], which also found an increased risk from inhaled fenoterol (compared with other betaagonist, such as salbutamol) in the $200 \mu \mathrm{g}$ dose in which it was marketed. This study also raised concerns about a general beta-agonist class effect, based on secondary analyses which suggested that the fenoterol and salbutamol risks may have been similar if fenoterol had been marketed in a lower dose; however, the interpretation of this theoretical extrapolation awaits further study [5].

It has not been possible from these epidemiological studies to determine the mechanism(s) whereby fenoterol increases the risk of death in comparison with salbutamol or terbutaline, which have not been incriminated in asthma mortality epidemics [6]. However, experimental studies which have compared the pharmacological properties of different beta-adrenoceptor-agonists, have identified important differences between these agents [7, 8]. These differences relate to adverse effects resulting both from their long-term use, and from their use in high doses in an acute attack, and may be relevant to their differing potential to increase the risk of death when used by patients with severe asthma. Long-term use of fenoterol has been shown to lead to worsening asthma and reduced lung function, when compared with terbutaline [9]. The repeated self-administered use of the high dose preparation of fenoterol could result in increased adverse cardiac affects [8], more marked hypokalaemia [10], and a greater delay in seeking medical advice, compared with salbutamol or terbutaline.

Whatever, the mechanism(s) by which fenoterol increases the risk of death, it might be expected that fenoterol may also increase the risk of near-fatal attacks. This hypothesis has been supported by findings from the Saskatchewan study [4], which found that fenoterol (in 
the dose in which it was marketed) was associated with an increased risk of both fatal and near-fatal attacks of asthma, compared with the more commonly prescribed beta-agonist, salbutamol. This study also found that a number of other classes of asthma drugs, including oral theophylline, oral corticosteroids, inhaled corticosteroids and sodium cromoglycate, were also associated with an increased risk of fatal or near-fatal asthma. However, the lack of matching for asthma severity meant that their findings should be interpreted with caution, and certainly subsequent analyses have suggested a protective effect for inhaled corticosteroids [11].

To further investigate the possible role of different asthma therapies in the development of near-fatal asthma, we have conducted a case-control study of prescribed drug therapy and near-fatal asthma in New Zealand during 1977-1988, the period of the mortality epidemic.

\section{Methods}

A case-control design has been used to compare the regular prescribed drug therapy of asthmatic patients suffering near-fatal attacks of asthma and that of asthmatic patients suffering severe attacks requiring admission to hospital but in whom death was not imminent. As in previous studies, attention has been focused on the 5-45 yrs age-group, because death from asthma is a reasonably clear cut diagnosis in this group [12].

\section{Selection of cases}

The eligible cases comprised all persons aged 5-45 yrs who were admitted to the Intensive Care Units (ICUs) of Wellington or Hutt Hospital during the period 1977-1988 with a diagnosis of asthma.

\section{Selection of controls}

For each case, two controls were selected at random from hospital records of patients discharged from Wellington or Hutt Hospital with a diagnosis of asthma (but who were not admitted to the ICU) in the year in which the case was admitted. The controls were matched on hospital and on age (within 5 yrs). If sufficient controls could not be obtained, then the age-range was widened to $10 \mathrm{yrs}$; however, all controls were chosen from within the 5-45 yrs age range.

\section{Information on prescribed drug therapy}

For all cases and controls, hospital records were used as the information source for prescribed drug therapy at time of admission. Information was recorded from the case notes, Emergency Department notes, general practitioner letters, and other sources. It was not possible to perform the data extraction "blind", but the data extractors were instructed to record all drug information from these sources. When more than one record was available from a particular source (e.g. in the case notes), then the record with the most complete drug information was used. The data forms were copied, and all information which identified cases and controls was deleted. Two members of the study team ( $\mathrm{CB}$ and JC) then made a blind assessment of the drugs on admission.

The drug therapy for those cases and controls with a hospital admission for asthma during the previous 12 months was also collected from that admission and assessed "blind". As in previous studies [1-3], the possibility of confounding or effect modification by severity was assessed by considering various subgroups defined by markers of chronic severity: 1) three or more prescribed categories of asthma drugs at time of admission; 2) a hospital admission for asthma during the previous 12 months (prior to the admission under consideration); and 3) prescribed oral corticosteroids at time of admission. These markers have been shown to identify patients with severe asthma at increased risk of hospital admission or death from asthma [13].

\section{Data analysis}

The Mantel and Haenszel [14] procedure was used to calculate odds ratios (ORs) and test-based confidence intervals (CIs) [15]. Logistic regression [16] was also used to calculate ORs adjusted for potential confounders. This is analagous to a stratified analysis, but enables the control of additional confounders, simultaneously, in the model.

As in previous studies, the standard approach of considering each beta-agonist independently was used, and the small group of patients who were prescribed both fenoterol and salbutamol were considered to be "exposed" to both drugs.

\section{Results}

Identifying details were obtained from hospital records for 180 persons aged 5-45 yrs who were admitted to the ICU with asthma (International Classification of Disease (ICD) code 493) during the period 1977-1988. The search of hospital records actually identified personal records for $155(86 \%)$ of these patients. Some records could not be found and may have been discarded, because in some instances the last admission had occurred more than 10 yrs previously. For each case, two matched controls were selected, although in a few instances only one control could be obtained. The study thus involved a total of 155 cases and 305 matched controls. Eighty four of the cases and 122 of the controls had had a previous admission for asthma (to any hospital) during the previous 12 months, and the relevant admission records were found at Wellington or Hutt Hospital for 65 (77\%) of these cases and $104(85 \%)$ of the controls.

The case group was $39 \%$ male, and had a mean age of $26 \mathrm{yrs}$; the control group was $40 \%$ male, and had a mean age of 26 yrs. 
Table 1. - Prescribed drug therapy on admission, markers of chronic asthma severity, and the relative risk of admission to ICU

\begin{tabular}{|c|c|c|c|c|c|c|c|}
\hline \multirow[t]{2}{*}{ Prescribed drug therapy on admission } & \multicolumn{2}{|c|}{ Cases } & \multicolumn{2}{|c|}{ Controls } & \multirow{2}{*}{$\begin{array}{l}\text { Odds } \\
\text { ratio }\end{array}$} & \multirow[t]{2}{*}{$95 \%$ CI } & \multirow{2}{*}{$\begin{array}{c}\mathrm{p} \\
\text { value }\end{array}$} \\
\hline & Yes & $\overline{\text { No }}$ & Yes & $\overline{\mathrm{No}}$ & & & \\
\hline Oral beta-agonists & 32 & 123 & 52 & 253 & 1.27 & $0.78-2.07$ & 0.35 \\
\hline Salbutamol & 29 & 126 & 47 & 258 & 1.26 & $0.76-2.10$ & 0.37 \\
\hline Beta-agonists by MDI & 139 & 16 & 289 & 16 & 0.48 & $0.24-0.98$ & 0.04 \\
\hline Fenoterol & 71 & 84 & 90 & 215 & 2.02 & $1.36-3.01$ & $<0.01$ \\
\hline Salbutamol & 71 & 84 & 200 & 105 & 0.44 & $0.30-0.66$ & $<0.01$ \\
\hline Beta-agonists by nebulizer & 11 & 144 & 18 & 287 & 1.22 & $0.56-2.65$ & 0.62 \\
\hline Fenoterol & 4 & 151 & 5 & 300 & 1.60 & $0.43-5.95$ & 0.49 \\
\hline Salbutamol & 7 & 148 & 14 & 291 & 0.98 & $0.39-2.49$ & 0.97 \\
\hline All inhaled beta-agonists & 141 & 14 & 291 & 14 & 0.49 & $0.23-1.03$ & 0.06 \\
\hline Fenoterol & 73 & 82 & 94 & 211 & 2.00 & $1.35-2.97$ & $<0.01$ \\
\hline Salbutamol & 76 & 79 & 205 & 100 & 0.47 & $0.32-0.70$ & $<0.01$ \\
\hline Oral theophyllines & 100 & 55 & 150 & 155 & 1.88 & $1.26-2.79$ & $<0.01$ \\
\hline Sodium cromoglycate & 15 & 140 & 24 & 281 & 1.25 & $0.64-2.47$ & 0.51 \\
\hline Inhaled corticosteroids & 98 & 57 & 170 & 135 & 1.37 & $0.92-2.03$ & 0.12 \\
\hline \multicolumn{8}{|l|}{ Markers of chronic asthma severity } \\
\hline $\begin{array}{l}\text { Three or more categories } \\
\text { of asthma drugs on admission }\end{array}$ & 87 & 68 & 129 & 176 & 1.75 & $1.18-2.58$ & 0.01 \\
\hline Admission in previous 12 months & 84 & 71 & 122 & 183 & 1.78 & $1.20-2.62$ & $<0.01$ \\
\hline $\begin{array}{l}\text { Oral corticosteroids } \\
\text { on admission }\end{array}$ & 49 & 106 & 68 & 237 & 1.61 & $1.05-2.48$ & 0.03 \\
\hline
\end{tabular}

ICU: Intensive Care Unit; 95\% CI: 95\% confidence interval; MDI: metered dose inhaler.

Table 1 shows the relative risks of ICU admission associated with prescribed drug therapy at the time of admission. In many instances, it was difficult to determine from the hospital records whether oral corticosteroids had been prescribed as a continuous or short course. The data for oral corticosteroids, thus, refer to any prescribed oral corticosteroids (continuous, short course, or unknown regimen).

The relative risk for an ICU admission was 2.02 in patients prescribed fenoterol by metered dose inhaler (MDI), and 1.60 in patients prescribed fenoterol by nebulizer (the numbers were very small for this latter comparison). The overall relative risk for inhaled fenoterol was 2.00. Although most other asthma drugs (with the exception of salbutamol) also showed some positive association with ICU admissions the only other strong association was for oral theophyllines $(\mathrm{OR}=1.88)$.

All three markers of chronic asthma severity were associated with ICU admissions, (table 1), with ORs of 1.75 for three or more categories of asthma drugs on admission, 1.78 for an admission in the previous 12 months, and 1.61 for prescribed oral corticosteroids on admission.

The inhaled fenoterol relative risk generally tended to increase (but not substantially) when the analysis was restricted to subgroups defined by markers of chronic asthma severity: in those prescribed three or more categories of asthma drugs, the inhaled fenoterol relative risk was 1.61 (95\% CI 0.93-2.78); in those with a hospital admission in the previous 12 months it was 2.58 (95\% CI 1.46-2.55); in those prescribed oral corticosteroids it was 2.34 (95\% CI 1.11-4.95); and in those with the most severe asthma (defined by an admission in the previous 12 months and prescribed oral corticosteroids at time of admission) it was 2.93 (95\% CI
1.16-7.42). With the exception of oral theophyllines, other asthma drugs did not show the same elevation in risk when the analysis was restricted in this manner (table 2).

The analysis was also repeated (using records from the previous admission) for the 65 cases and 104 controls who had a previous hospital admission for asthma in the previous 12 months, in order to examine the regular prescribed medication prior to the near-fatal attack. As in previous studies which used a similar approach $[2,3]$, the prescribed drug therapy was assessed on discharge, with the exception of the markers of chronic asthma severity, which were assessed at time of admission. The findings (table 3 ) were generally similar to those in the overall analysis (table 1), with ORs of 2.18 for inhaled fenoterol and 1.88 for oral theophylline. Once again, some other asthma drugs showed minor elevations in risk, and cases were generally prescribed more asthma drugs than controls; however, for individual asthma drugs, only the findings for inhaled fenoterol and oral theophylline were markedly elevated.

The findings in table 1 and 2 were explored further by using logistic regression to adjust for a number of factors which showed positive association (inhaled fenoterol, oral theophylline, a hospital admission in the previous 12 months, and prescribed oral corticosteroids). When this was done, the overall OR for inhaled fenoterol decreased slightly to 1.79 (95\% CI 1.19-2.64), but the oral theophylline ORs decreased to 1.44 (95\% CI $0.92-2.25)$; the OR for inhaled steroids $(\mathrm{OR}=1.05 ; 95 \%$ CI 0.69-1.61) also decreased substantially, but that for sodium cromoglycate did not change $(\mathrm{OR}=1.25 ; 95 \% \mathrm{CI}$ $0.63-2.50)$. The marked reduction for oral theophylline occurred because prescribing of this drug was associated with asthma severity: $52 \%$ of those prescribed oral 
Table 2. - Prescribed drug therapy on admission and the relative risk of admission to ICU: odds ratios (and 95\% $\mathrm{Cls}$ ) in subgroups defined by markers of chronic asthma severity

\begin{tabular}{|c|c|c|c|c|}
\hline \multicolumn{2}{|l|}{ Three or more } & \multicolumn{2}{|c|}{ Admission } & \multirow[b]{2}{*}{$\begin{array}{l}\text { and oral } \\
\text { corticosteroids }\end{array}$} \\
\hline $\begin{array}{ll}\text { Prescribed drug } & \text { cate } \\
\text { therapy on } & \text { dru } \\
\text { discharge } & \text { adn }\end{array}$ & $\begin{array}{l}\text { ries of } \\
\text { on } \\
\text { sion }\end{array}$ & $\begin{array}{l}\text { Admission in } \\
\text { previous year }\end{array}$ & $\begin{array}{c}\text { previous year } \\
\text { Oral corticosteroids } \\
\text { on admission }\end{array}$ & \\
\hline \multirow[t]{2}{*}{ Oral beta-agonist } & 0.93 & 0.96 & 1.17 & 0.93 \\
\hline & $0.49-1.74$ & $0.47-1.95$ & $0.50-2.74$ & $0.33-2.65$ \\
\hline \multirow[t]{2}{*}{ Inhaled beta-agonists } & 1.01 & 0.26 & 0.47 & - \\
\hline & $0.17-6.21$ & $0.06-1.26$ & $0.08-2.80$ & - \\
\hline \multirow[t]{2}{*}{ Fenoterol } & 1.61 & 2.58 & 2.34 & 2.93 \\
\hline & $0.93-2.78$ & $1.46-4.55$ & $1.11-4.95$ & $1.16-7.42$ \\
\hline \multirow[t]{2}{*}{ Salbutamol } & 0.67 & 0.44 & 0.44 & 0.38 \\
\hline & $0.38-1.16$ & $0.25-0.77$ & $0.21-0.92$ & $0.15-0.96$ \\
\hline \multirow[t]{2}{*}{ Oral theophyllines } & 1.01 & 2.40 & 1.38 & 2.06 \\
\hline & $0.35-2.96$ & $1.25-4.59$ & $0.47-4.04$ & $0.48-8.82$ \\
\hline \multirow[t]{2}{*}{ Sodium cromoglycate } & 1.56 & 1.51 & 0.99 & 0.82 \\
\hline & $0.67-3.64$ & $0.57-3.60$ & $0.29-3.34$ & $0.20-3.37$ \\
\hline \multirow{2}{*}{ Inhaled corticosteroids } & 0.78 & 0.84 & 1.03 & 0.93 \\
\hline & $0.37-1.64$ & $0.45-1.56$ & $0.44-2.42$ & $0.33-2.60$ \\
\hline \multirow{2}{*}{ Oral corticosteroids } & 1.12 & 1.68 & - & - \\
\hline & $0.65-1.94$ & $0.94-2.98$ & - & - \\
\hline
\end{tabular}

95\% CIs: $95 \%$ confidence intervals.

Table 3. - Prescribed drug therapy on discharge (from a previous admission in the previous 12 months), markers of chronic asthma severity, and the relative risk of admission to ICU

\begin{tabular}{|c|c|c|c|c|c|c|c|}
\hline \multirow[b]{2}{*}{ Exposure } & \multicolumn{2}{|c|}{ Cases } & \multicolumn{2}{|c|}{ Controls } & \multirow{2}{*}{$\begin{array}{l}\text { Odds } \\
\text { ratio }\end{array}$} & \multirow[t]{2}{*}{$95 \% \mathrm{CI}$} & \multirow{2}{*}{$\begin{array}{c}\mathrm{p} \\
\text { value }\end{array}$} \\
\hline & Yes & No & Yes & No & & & \\
\hline \multicolumn{8}{|c|}{ Prescribed drug therapy on discharge } \\
\hline Oral beta-agonists & 8 & 57 & 25 & 79 & 0.44 & $0.19-1.04$ & 0.06 \\
\hline Salbutamol & 8 & 57 & 24 & 80 & 0.47 & $0.20-1.10$ & 0.08 \\
\hline Beta-agonists by MDI & 50 & 15 & 78 & 26 & 1.11 & $0.54-2.31$ & 0.78 \\
\hline Fenoterol & 24 & 41 & 22 & 82 & 2.18 & $1.10-4.33$ & 0.03 \\
\hline Salbutamol & 28 & 37 & 56 & 48 & 0.65 & $0.35-1.21$ & 0.17 \\
\hline \multicolumn{8}{|l|}{ Beta-agonists by } \\
\hline Nebulizer & 3 & 62 & 6 & 98 & 0.79 & $0.19-3.28$ & 0.75 \\
\hline Fenoterol & 1 & 64 & 1 & 103 & 1.61 & $0.10-25.7$ & 0.74 \\
\hline Salbutamol & 2 & 63 & 5 & 99 & 0.63 & $0.12-3.31$ & 0.58 \\
\hline All inhaled beta-agonists & 50 & 15 & 81 & 23 & 0.95 & $0.45-1.99$ & 0.89 \\
\hline Fenoterol & 24 & 41 & 22 & 82 & 2.18 & $1.10-4.33$ & 0.03 \\
\hline Salbutamol & 29 & 36 & 60 & 44 & 0.59 & $0.32-1.10$ & 0.10 \\
\hline Oral theophyllines & 43 & 22 & 53 & 51 & 1.88 & $0.99-3.57$ & 0.05 \\
\hline Sodium cromoglycate & 6 & 59 & 7 & 97 & 1.41 & $0.45-4.39$ & 0.55 \\
\hline Inhaled corticosteroids & 45 & 20 & 66 & 38 & 1.30 & $0.67-2.51$ & 0.44 \\
\hline Oral corticosteroids & 38 & 27 & 70 & 34 & 0.68 & $0.36-1.30$ & 0.25 \\
\hline $\begin{array}{l}\text { Three or more categories } \\
\text { of asthma drugs }\end{array}$ & 49 & 16 & 66 & 38 & 1.76 & $0.89-3.51$ & 0.11 \\
\hline \multicolumn{8}{|c|}{ Markers of chronic asthma severity } \\
\hline $\begin{array}{l}\text { Three or more categories } \\
\text { of asthma drugs on admission }\end{array}$ & 45 & 20 & 53 & 51 & 2.17 & $1.13-4.14$ & 0.02 \\
\hline $\begin{array}{l}\text { Admission in previous } \\
12 \text { months }\end{array}$ & 50 & 15 & 50 & 54 & 3.60 & $1.83-7.10$ & $<0.01$ \\
\hline $\begin{array}{l}\text { Oral corticosteroids } \\
\text { on admission }\end{array}$ & 23 & 42 & 21 & 83 & 2.16 & $1.08-4.33$ & 0.03 \\
\hline
\end{tabular}

For abbreviations see legend to table 1.

theophylline had a previous hospital admission in the previous 12 months compared with $32 \%$ of those not prescribed oral theophylline (the corresponding figures for inhaled fenoterol were 44 and $41 \%$ ).

Similar results were obtained for the analysis using data from previous admissions: the adjusted ORs were 1.99 (95\% CI 0.95-4.17) for inhaled fenoterol, 1.85 (95\% CI 0.93-3.70) for oral theophylline, 1.08 (95\% CI 0.31-3.69) for sodium cromoglycate, and 1.27 (95\% CI 0.57-2.85) for inhaled steroids. 


\section{Discussion}

The findings presented here on prescribed drug therapy and near-fatal asthma attacks complement the previous studies of fatal asthma attacks [1-5], and are consistent with the hypothesis that inhaled fenoterol increases the risk of near-fatal attacks as well as fatal attacks. However, this finding, and those relating to other asthma drugs such as oral theophylline, should be interpreted cautiously, since there were significant differences in chronic asthma severity between cases and controls despite the use of hospital admission controls.

The study design was similar to that in our first casecontrol study of asthma deaths [1], where it was found that the use of hospital admission controls provided an adequate indirect match for chronic asthma severity, in that asthma deaths and hospital admission controls were similar with respect to recognized markers of chronic asthma severity [13]. However, in the current study, there were significant differences in chronic asthma severity between cases and controls. In the previous study [1], $32 \%$ of cases and $32 \%$ of controls (excluding those prescribed fenoterol) had a previous hospital admission for asthma in the previous 12 months; in the current study the corresponding estimates were 46 and $39 \%$. Similarly, in the previous study, $42 \%$ of cases and $40 \%$ of controls (excluding those prescribed fenoterol) were prescribed three or more categories of asthma drugs, whereas the corresponding estimates in the current study were 50 and $36 \%$. These differences between cases and controls in the current study were apparent not only at the time of the admission under study (the ICU admission for cases and the hospital admission for the controls), but also at the time of previous hospital admissions for asthma in the previous 12 months. Overall, the cases of near-fatal asthma attacks had chronic asthma severity which was not only greater than that of the hospital admission controls, but was also greater than that observed in previous studies involving asthma deaths [1-3]. Thus, whilst confounding by severity was not a major concern in the interpretation of the previous studies [17, 18], it cannot be excluded as an explanation for the findings of the current study, although it should be emphasized that there is little evidence of selective prescribing of fenoterol to more severe asthmatics in New Zealand [18].

Despite these reservations, the findings of the current study are of considerable interest. Fenoterol was associated with near-fatal asthma attacks; this association was slightly stronger within the subgroup of patients with more severe asthma, and was only slightly weakened when the findings were adjusted for oral theophylline and for markers of asthma severity, implying that the findings are unlikely to be due to confounding by severity. These findings are consistent with those in previous New Zealand case-control studies of fatal asthma attacks [1-3], and also with the findings of the Saskatchewan case-control study of fatal and near fatal attacks [4].

Prescribed oral theophylline was also associated with near-fatal attacks, but there was some evidence of selective prescribing of oral theophylline, and the association decreased when the findings were adjusted for fenoterol and for markers of chronic asthma severity (implying that confounding by severity may be more of a problem in the oral theophylline analyses). Previous New Zealand studies of fatal attacks [1-3] have found relative risks for oral theophylline of $1.44,1.10$, and 1.09 , respectively, whereas the Saskatchewan case-control study found crude ORs of 3.7 for asthma deaths and 3.7 for asthma deaths and near-deaths combined. Thus, unlike the fenoterol findings, the oral theophylline findings are inconsistent across the various studies. The main positive findings for oral theophyllines are in the current study, and in the Saskatchewan study [4], and in both instances there is concern about the comparability of the cases and controls with respect to chronic asthma severity [19] (and, hence, about the possibility of confounding by severity). Nevertheless, the findings for oral theophylline are of interest, in light of concern about its safety, both alone and in combination with beta-adrenoceptor-agonists [20, 21].

The findings for other asthma drugs were generally unremarkable. Although cases were generally prescribed more asthma drugs than controls (presumably because of the differences in chronic asthma severity discussed above), the relative risks for drugs other than inhaled fenoterol and oral theophylline were not markedly or significantly elevated. Furthermore, the relative risks tended to decrease when the data were adjusted for fenoterol, oral theophylline and markers of chronic asthma severity. In particular, there was no increased risk found for salbutamol, or for the general class of inhaled betaadrenoceptor-agonist drugs. This is consistent with the findings of previous New Zealand studies [1-3], and with the "crude" findings of the Saskatchewan study [4], and supports the view that the "adjusted" findings from the Saskatchewan study may reflect inadequate matching for asthma severity [19].

In summary, despite our reservations regarding possible differences in asthma severity between cases and controls, this study provides a useful complement to previous case-control studies of deaths and near-deaths from asthma [1-6]. It is consistent with previous evidence that fenoterol increases the risk of near-fatal [4], as well as fatal [1-4] asthma attacks. In addition, it provides some support to previous concerns about the safety of oral theophyllines [4], although the evidence in this regard is more limited and less consistent [1-4].

Acknowledgements: The authors wish to thank the superintendents of the hospitals visited for their help and cooperation in providing access to the hospital admission records, the staff of the medical records departments for their help in obtaining records, S. Marshall for assistance with data management, and A. Hayman for typing the manuscript. They also wish to thank the Health Research Council of New Zealand for funding this study. NP and JC are supported by Senior Research Fellowships of the Health Research Council of New Zealand.

\section{References}

1. Crane J, Pearce NE, Flatt A, et al. Prescribed fenoterol and death from asthma in New Zealand, 1981-83: casecontrol study. Lancet 1989; i: 517-522. 
2. Pearce NE, Grainger J, Atkinson M, et al. Case-control study of prescribed fenoterol and death from asthma in New Zealand, 1977-1981. Thorax 1990; 45: 170-175.

3. Grainger J, Woodman K, Pearce NE, et al. Prescribed fenoterol and death from asthma in New Zealand, 1981-1987: a further case-control study. Thorax 1991; 46: 105-111.

4. Spitzer WO, Suissa S, Ernst P, et al. The use of betaagonists and the risk of death and near death from asthma. N Engl J Med 1992; 326: 501-506.

5. Crane J, Burgess C, Pearce N, Beasley R. The $\beta$-agonist controversy: a perspective. Eur Respir Rev 1993; 3: 475-482.

6. Woodman K, Pearce NE, Beasley R, Burgess C, Crane J. Albuterol and deaths from asthma in New Zealand from 1969 to 1976: a case-control study. Clin Pharmacol Ther 1992; 51: 566-571.

7. Pearce NE, Crane J, Burgess C, Jackson R, Beaslsy R. Beta-agonists and asthma mortality: déjà vu. Clin Exp Allergy 1991; 21: 401-410.

8. Beasley R, Pearce NE, Crane J, Windom H, Burgess C. Asthma mortality and inhaled beta-agonist therapy. Aust NZ J Med 1991; 21: 753-763.

9. Trembath PW, Greenacre JK, Anderson M, et al. Comparison of 4 weeks' treatment with fenoterol and terbutaline aerosols in adult asthmatics. J Allergy Clin Immunol 1979; 63: 395-400.

10. Haalboom JRE, Deenstrom M, Stuyvenberg A. Hypokalaemia induced by inhalation of fenoterol. Lancet 1985; i: $1125-1127$.

11. Spitzer W. The Saskatchewan case-control study of $\beta$ agonist. In: Costello JF, Mann RD, eds. Beta Agonists in the Treatment of Asthma. New York, Parthenon Publishing Group Ltd, 1992. pp. 89-109.
12. Sears MR, Rea HH, de Boer G. et al. Accuracy of certification of deaths due to asthma: a national study. Am J Epidemiol 1986; 124: 1004-1011.

13. Crane J, Pearce NE, Burgess C, Woodman K Robson B, Beasley R. Markers of risk of asthma death or readmission in the 12 months of following a hospital admission for asthma. Int $J$ Epidemiol 1992; 21: $1-8$.

14. Mantel N, Haenszel W. Statistical aspects of the analysis of data from retrospective studies of disease. J Natl Cancer Inst 1959; 22: 719-748.

15. Miettinen OS. Estimability and estimation in casereferent studies. Am J Epidemiol 1976; 103: 226-235.

16. Harrell F. The Logist procedure. In: SAS Supplemental Library User's Guide. Cary, North Carolina; SAS Institute, 1983.

17. Pearce NE, Crane J, Burgess C, Beasley R, Jackson R. Fenoterol and asthma mortality. Lancet 1989; i: 1196-1197, (letter).

18. Beasley R, Pearce NE, Burgess C, Grainger J, Crane J. Confounding by severity does not explain the association between fenoterol and asthma death. Clin Exp Allergy, (in press).

19. Pearce NE, Crane J, Burgess C, Jackson R, Beasley R. Fenoterol, beta-agonists and asthma deaths. $N$ Engl $J$ Med 1992; 327: 355-356, (letter).

20. Wilson JD, Sutherland DC, Thomas AC. Has the change to beta-agonists combined with oral theophylline increased cases of fatal asthma? Lancet 1981; i: 1235-1237.

21. Flatt A, Burgess C, Windom H, Beasley R, Purdie G, Crane J. The cardiovascular effects of inhaled fenoterol and during treatment with oral theophylline. Chest 1989; 96: $1317-1320$. 